\title{
José Martí: el hombre y su tiempo. Problemas para la anotación de los textos martianos desde la experiencia de una edición crítica
}

Pedro Pablo Rodríguez

\section{Recommended Citation}

Rodríguez, Pedro Pablo. 2010. José Martí: el hombre y su tiempo. Problemas para la anotación de los textos martianos desde la experiencia de una edición crítica. Revista Surco Sur, Vol. 1: Iss. 1, 47-53. DOI: http://dx.doi.org/10.5038/2157-5231.1.1.13

Available at: https://digitalcommons.usf.edu/surcosur/vol1/iss1/15

This NUESTRA AMÈRICA is brought to you for free and open access by the Open Access Journals at Digital Commons@ University of South Florida. It has been accepted for inclusion in Revista Surco Sur by an authorized editor of Digital Commons @ University of South Florida. For more information, please contact digitalcommons@usf.edu. 


\section{Pedro Pablo Rodríguez}

José Martí: el hombre y su tiempo. Problemas para la anotación de los textos martianos desde la experiencia de una edición crítica.

El trabajo de la edición crítica de las Obras completas de José Martí, bajo mi dirección en el Centro de Estudios Martianos, la experiencia acumulada por esta institución durante más de treinta años con la edición de sus escritos, más los tantos años que he dedicado al estudio de su vida y su obra, me han llevado a ordenar algunas prácticas con el manejo de sus escritos que pueden resultar de interés para la investigación en torno a sus textos y sus ideas, así como para la edición de aquellos.

Aspectos metodológicos generales para el estudio de la obra escrita martiana y de su pensamiento.

El pensamiento del Maestro no aparece expuesto de forma orgánica en textos destinados a esos efectos, sino que se despliega a lo largo de una verdadera "selva" de escritos de muy diferente naturaleza e intencionalidad. El patriota cubano nunca escribió un libro contentivo de una exposición sistematizada de su cosmovisión o de algunos aspectos de su ideario, aunque así lo planeara frecuentemente, sino que para ello se valió de las más diversas formas de la escritura, abarcando desde la expresión definidamente ficcional (poesía, cuento y teatro) hasta el periodismo en su más amplia variedad de géneros (ensayo, artículo, crónica, editorial, sueltos y gacetillas),

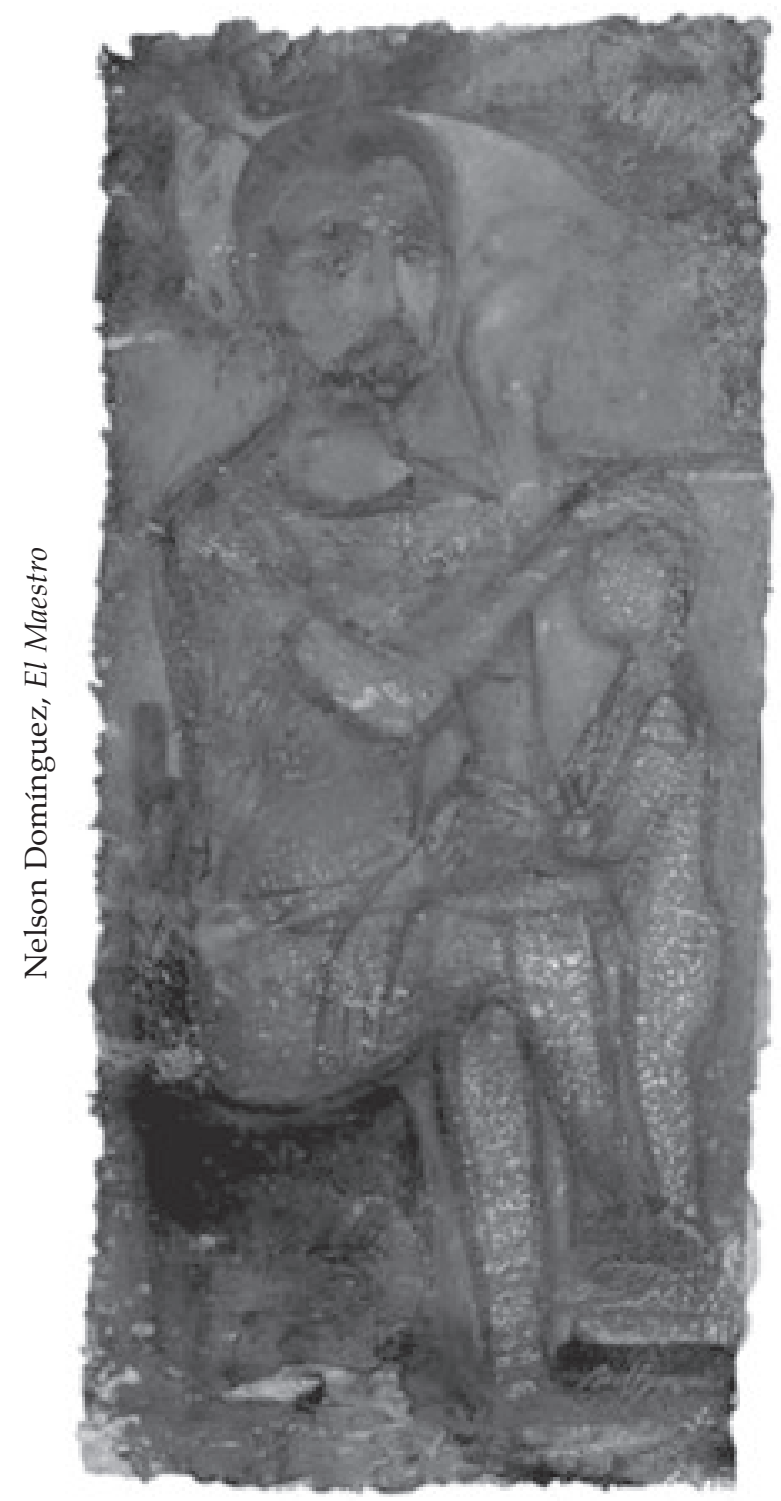
desde la oratoria hasta la epístola, sin excluir sus cuadernos de apuntes o anotaciones y hasta sus traducciones.

La enorme cantidad de páginas que escribiera, junto a su variedad temática y genérica determinadas en medida significativa por los distintos propósitos comunicacionales que le animaran a redactarlas, no sólo implican consideraciones diferentes a la hora del análisis literario, sino, también, en el momento de considerarlas para organizar y explicar sus ideas, todo lo cual, desde luego, también influye en los criterios para su edición.

A manera de ejemplos, es obvio que no sólo son diferentes literariamente un poema, una carta, una crónica periodística o un discurso, sino que, además, fueron documentos escritos con objetivos bien distintos, aunque los cuatro pretendan establecer una comunicación con los destinatarios respectivos. El poema está abierto a cualquier lector y no pretende describir ni explicar algo de la realidad sino traspasar una emoción o un sentimiento. La crónica periodística quiere informar desde la perspectiva particular del periodista, y, cuando más, desea inducir a la reflexión a un universo relativamente amplio y diverso de lectores. La carta es para un destinatario (o varios), pero no para lectores desconocidos; no es pública generalmente sino del ámbito privado, y en el caso martiano cumple muchas funciones, que pueden variar según los casos, como entre otras, informar, influir en las ideas del otro, compartir espiritualmente. El discurso, finalmente, aunque se escriba previamente y no sea improvisado se sustenta en la comunicación oral directa frente a un auditorio, y por ello es incomprensible a plenitud sin 
el tono y la modulación de la voz, sin el gesto, sin el ambiente en el lugar en que se pronuncia y entre el orador y su público.

Los límites de cada texto para determinar su alcance pasan entonces, indudablemente, por su relación con los receptores: el periodismo está sometido a los criterios censores del editor, el discurso a la audiencia, en la carta la única limitación del autor es la que le impone el destinatario casi siempre único, mientras que quizás en el poema es donde el autor se muestra más libre, más en su verdadero yo.

La verdadera evaluación, pues, del documento escrito y de su alcance para determinar cómo estimarlo para conocer el ideario de su autor y las estrategias comunicacionales seguidas durante su redacción, no puede en modo alguno evadir las preguntas de para quién o quiénes se ha escrito y por qué medios llegará a su lector, según lo concebido por el autor.

Todo esto se hace particularmente significativo en el caso de Martí, autor de intensa vida pública como periodista y como político, quien, además, tuvo alta conciencia, cumplida siempre con responsabilidad absoluta, del valor y el sentido de su escritura, no sólo para su época sino para el futuro.

Por otro lado, al mismo tiempo que ha de partirse de esa variedad formal y de intencionalidad de sus escritos, y de esa dispersión de su pensamiento en ellos, ambos - su escritura y su pensamiento - han de ser concebidos y analizados como una totalidad. No sólo es ello una indicación metodológica imprescindible al acercarnos a cualquier escritor y pensador, dado que más allá de sus cambios de opinión y de vida se trata de la misma persona, sino que en el caso de Martí se unen tanto una característica voluntad expresa de autoctonía y originalidad, como una verdadera unidad de perspectivas, enfoques y temas, que se van desarrollando progresivamente e interrelacionando con mayor precisión según avanza la vida del Maestro.

A diferencia de otros pensadores, el cubano no evidencia rompimientos ni cambios epistemológicos ni saltos en su ideario: es uno y el mismo de principio a fin con el lógico desarrollo, según pasa el tiempo, de sus capacidades expresivas y de la riqueza de sus análisis.

El adolescente que madura precozmente en La Habana y el joven que termina sus estudios secundarios y aprueba los superiores durante su primera deportación a España es el mismo hombre que madura en Nueva York atendiendo cuidadosamente a los cambios que ocurrían entonces en la sociedad estadounidense y en el mundo moderno en general, y es también el mismo tenaz, osado y brillante estadista que organiza el Partido Revolucionario Cubano para, con la independencia de Cuba, buscar un equilibrio del mundo de su tiempo.

Las bases o fundamentos de su pensar y de actuar serán siempre los mismos: un marcado sentido de la originalidad y la autoctonía, tanto en el plano individual como en el social, y lo mismo en el terreno literario y de las ideas como en las formas de organización política y social; una ética de servicio humano que dará alcance sacrificial a su vida y a su obra; y una clara y definida toma de partido con los pobres de la tierra y los pueblos dominados.

Tales principios, apreciables más de una vez desde sus escritos de jovencito, se entrecruzan e interpenetran en él de tal modo que puede afirmarse se compactan con la propia lógica de su pensar, más metafórica que racionalista, sin desdeñar este último, y que sabe integrar los saberes de la tradición moderna occidental con los de la antigüedad clásica europea y asiática, y con lo que estuvo a su alcance entonces del pensamiento de los antiguos pueblos del continente americano.

La lógica martiana no fue la de la ganancia capitalista, ni la de la conquista de la naturaleza por el hombre, ni la del progreso rectilíneo y uniforme, sino la de la permanente búsqueda de la armonía del hombre y la sociedad como entes naturales, la de la liberación espiritual de los seres humanos, y la del reconocimiento de las diversidades culturales y civilizatorias.

Fue Martí - y cada día lo comprendemos mejor - un lúcido crítico de la modernidad industrial capitalista que se apoderaba del orbe entonces, sin ser un antimoderno o un premoderno tradicionalista. Sin embargo, le sedujeron la agitación y el cambio incesante de la vida moderna que vivió a diario en Nueva York, disfrutó los arrebatos tecnológicos y los descubrimientos científicos más diversos (desde la luz eléctrica hasta la máquina de escribir), sin rendir culto jamás al cientificismo positivista porque fue siempre un preocupado por el alma humana, por su espiritualidad, sin el dogmatismo de religión alguna.

Su mente siempre inquieta e indagadora no se sobrepuso a su ética humanista: para él - lo escribió así - pensar era servir. Luego pensar era estar al servicio del bien del hombre. 
Por eso la lógica de su discurso, la argumentación de sus ideas y sus análisis de los problemas cubanos y universales de su tiempo pueden combinar con fuerza creadora y convincente la razón moderna que desecha al escolasticismo, las tradiciones de autoctonía hispanoamericana, el uso desprejuiciado de la mirada de las filosofías antiguas del Oriente sobre la mente del hombre y una expresión metafórica que procede mediante analogías, al igual que su estilo mezcló los clásicos antiguos y españoles, los nuevos rumbos de la poesía francesa, la precisión del inglés moderno de Estados Unidos y creo una palabra, su palabra, plena de singularidades absolutamente irrepetibles.

Su lógica, su pensamiento y su estilo fundamentaron una sensibilidad y una conciencia de la contramodernidad capitalista, necesarias entonces y hoy para de veras avanzar hacia y por el desarrollo de la sociedad y del hombre.

De ahí, pues, las especiales consideraciones que nos plantea la hermenéutica de los textos martianos para una labor editorial.

\section{La edición crítica de las Obras completas.}

La idea se había venido moviendo desde los años 70 del siglo pasado entre los estudiosos de Martí, y comenzó a hacerse realidad poco después de fundado el Centro de Estudios Martianos en 1977, cuando Cintio Vitier y Fina García-Marruz elaboraron el proyecto inicial.

La edición de los escritos de Martí había alcanzado con las Obras completas de la Editorial Nacional de Cuba un notable grado de completez en cuanto al número de documentos, pero habían mantenido similar criterio editorial al seguido por Gonzalo de Quesada y Aróstegui y su hijo y continuador, Gonzalo de Quesada y Miranda, en cuanto al ordenamiento siguiendo las orientaciones martianas en su llamada carta testamento literario al primero de los Quesadas.

Con su habitual sagacidad editorial, el Maestro dejó una agrupación temática de sus principales escritos de indudable interés para el lector. Pero, como se puede constatar en la mencionada carta, él no pensó entonces en que sus obras completas tendrían la pretensión de incluir la totalidad de su producción escrita, como las cartas, los cuadernos de apuntes, y hasta cualquier fragmento conservado de su puño y letra.
Evidentemente, Martí expresó una voluntad literaria a la hora de recoger sus escritos; por eso desechaba en aquella misiva todos los poemas que escribiera y publicara antes del cuaderno Ismaelillo. El escritor de fuste fue riguroso en su propio enjuiciamiento y, por otra parte, ni él mismo podía tener absoluta conciencia en 1895 del valor en todos los ámbitos que tendría cualquier texto suyo para la posteridad. Además, lo más frecuente en aquella época al editarse las obras completas de un escritor era incluir solamente lo publicado, pues los escritos que no estaban terminados ni autorizados por el autor a ser reproducidos para los lectores, se consideraban textos incompletos y hasta de nulo o escaso valor literario e interés editorial.

Pero la dimensión humana, política y simbólica de Martí para la nación cubana y su consistente reconocimiento como personalidad mayor de las Américas, además de los cambios en las concepciones editoriales de las obras completas aportados por el siglo XX, convirtieron rápidamente en una joya cualquiera de sus textos, no importa cuál fuera la función ni la evaluación literaria que le asignara su autor al escribirlo.

Por eso, aquel proyecto iniciador de la edición crítica decidió organizar los materiales de la serie siguiendo básicamente un orden cronológico, que no sería respetado de manera absoluta, pues la poesía, los cuadernos de apuntes, las traducciones y las dedicatorias se publicarían agrupados en cada caso, por considerar que tales tipos de textos requieren de esa reunión para su mejor comprensión. Al mismo tiempo, según las épocas o momentos de su vida y de su quehacer, se harían agrupaciones por géneros o tipos de escritos.

Por ejemplo, lo que escribiera durante su primera estancia en México, casi todo publicado en la Revista Universal, abarca las páginas finales del tomo 1, y los tomos 2 al 4 completos, pero cada uno de ellos reúne textos de naturaleza diferente: en el 1 están los que tratan directamente la independencia de Cuba; en el 2, los artículos; el 3 reúne por secciones las crónicas sobre Europa, la crítica de arte, y cuento y teatro; y el 4 agrupa una variedad de escritos: la sección de comentarios "Correo de los teatros", los boletines parlamentarios, los sueltos y gacetillas, otros artículos y el epistolario. Hay casos, como el del tomo 5, que incluye todo lo que escribiera en Guatemala, en que la variedad de los documentos es tal que lo aconsejable fue presentarlos en estricto orden cronológico. 
La idea esencial del proyecto era revisar nuevamente las transcripciones y ofrecer una lección de los textos lo más fiel posible, así como entregar la mayor cantidad de nuevos escritos que pudieran localizarse en archivos públicos y privados y en las colecciones de publicaciones periódicas de aquellos años. Se trataba también de incorporar la historia genética del texto mediante el señalamiento de las tachaduras, cambios y enmiendas introducidos por el autor en los manuscritos y de incluir un aparato referencial que a través de las llamadas Notas finales informara acerca de los diversos asuntos y personalidades mencionados en los escritos, en especial de aquellas personas y temas que resultaran de importancia capital para la historia de Cuba y para la propia vida y obra martianas. Por primera vez en las ediciones de las obras martianas también se incorporaba el índice de materias.

Detenido en su ejecución hacia 1985 luego de haber logrado la impresión de los dos primeros tomos más los dos de la Poesía completa, el proyecto fue retomado hacia 1992 en el Centro de Estudios Martianos, y tras casi un año de estudio por un grupo de trabajo bajo la dirección de Ramón de Armas, finalmente arrancó de nuevo la labor, que desde 1993 está bajo mi conducción.

En esta nueva fase se tomaron algunas decisiones que modificaron aspectos parciales del proyecto inicial como incorporar información a los índices de nombres y geográfico, de manera de dejar las notas al pie de página solamente para las variantes del texto original, la aclaración de los nombres mencionados, y las referencias contextuales o de información imprescindibles. También se determinó incluir, cuando fuere necesario, un índice cronológico de los textos de cada tomo.

Esta colección tiene características especiales que presentan problemas particulares. Primero, se trata de una serie cuyo contenido por tomos se va decidiendo sobre la marcha, es decir, no están definidos ni organizados los materiales por incluir desde un principio, y, segundo, la labor editorial requiere de numerosas investigaciones previas para definir tanto los textos martianos como el propio aparato crítico y el cuerpo referativo. $Y$, finalmente, dada la enorme producción escrita martiana, que se incrementa sin cesar, la edición crítica se convierte en una empresa monumental por la cantidad de documentos y páginas por procesar, es necesariamente de larga duración y su complejidad es de las mayores en todos los ordenes en virtud de la diversidad de los textos y sus riquezas literaria, de contenido e informativa.

Claro está que ese hacerse sobre la marcha implica dos grandes peligros. Por una parte, el que queden fuera del lugar correspondiente textos que se olviden o sean pasados por alto por desconocimiento de su publicación o porque sólo al estudiarse a fondo se comprenda que estaban mal datados en las ediciones previas. Y, por otro lado, que aparezcan textos desconocidos con posterioridad a la publicación del tomo correspondiente en fecha. Pero es imprescindible correr el riesgo dada la pretensión de que esta edición crítica circule lo más pronto posible para que sus resultados estén al alcance de los lectores contemporáneos.

Otros riesgos, quizás menores, pero no de escasa importancia editorial, son los errores en la información referativa que puedan ser apreciados en tomos subsiguientes, donde quedarían subsanados, o la desestimación de asuntos para aclarar en notas informativas y contextuales, que igualmente podrían añadirse en tomos subsiguientes en que se volviera sobre el asunto.

Aunque hasta la fecha no nos hemos percatado de caso alguno, es obvio que el largo tiempo que ocupa esta edición conlleva la decisión ya tomada de incluir al final de la serie cualquier documento adicional que no haya sido ubicado en su tomo correspondiente por 
cualquiera de las razones mencionadas. Del mismo modo, también al final irán uno o más tomos contentivos de los índices de nombres, geográfico, de materias y general de toda la colección, momento en el cual se podrá subsanar cualquier error informativo en ellos.

Todas estas características y problemas obligaron a realizar algunas tareas previas consideradas imprescindibles para organizar la labor de esta colección editorial, tales como preparar un índice universal de los escritos martianos con todo lo publicado o inédito conocido hasta el momento y de permanente actualización, agrupar los documentos siguiendo el criterio cronológico establecido para tener una aproximación al total de páginas y al número de tomos que podría alcanzar la serie, y crear las Normas Editoriales.

Esta última tarea perseguía el fin de unificar en la medida de lo posible el trabajo de los editores para mantener los rasgos comunes imprescindibles a lo que sería una colección. El trabajo ha confirmado lo que pensamos entonces: cada tomo es un libro en sí mismo con características propias, pero ha de mantenerse la unidad editorial de la serie.

Las Normas Editoriales, extensas y minuciosas, se han ido ampliando según han ido apareciendo nuevos asuntos $\mathrm{u}$ otros no previstos, y abarcan hasta precisiones acerca de cada una de las partes que integran el tomo, como la estructura informativa y la redacción de las notas y los índices.

También se ha determinado dividir el trabajo en dos grandes momentos, que llamamos el de investigación y el editorial, en el lógico entendido que no hay límites cerrados entre ellos y que el objetivo último de todo lo que se hace es imprimir la colección.

Durante la investigación de cada tomo hay varias fases. Se estudia primeramente el momento cronológico y de contenidos que debe abarcar el tomo para así determinar los textos que incluirá. Este contenido puede sufrir ajustes de acuerdo al número total de páginas que abarque y según una valoración previa del espacio que pudiera ocupar el cuerpo referativo dada la cantidad de entradas en los índices de nombre y geográfico y las notas que exijan los textos martianos. Por tanto, desde ese estudio se van preparando las entradas de dichos índices.

A continuación se establece o se fija el texto martiano. Este es el punto decisivo, el más importante de la investigación, pues se trata de establecer el texto "definitivo". Para ello se realiza el cotejo de los originales y las publicaciones o su transcripción en los casos de escritos inéditos o nunca antes publicados en compilaciones.

Cuando se trabaja con los documentos martianos hay que asumir problemas diferentes si se trata de manuscritos o de impresos.

Los manuscritos son muy complicados de manipular, dado el precario estado de conservación de algunos de ellos, la caligrafía de su autor y las tachaduras y enmiendas introducidas por este, factores todos que se extreman en los poemas, especialmente en sus famosos Versos libres, que nunca terminó, y en los que aparecen varias versiones de palabras, líneas de versos y hasta de composiciones completas sin demostrar decisión firme por alguna de ellas, o espacios en blanco indicativos de palabras pendientes.La caligrafía martiana es especialmente difícil de leer, pues sus nerviosos rasgos muestran por lo general que escribía muy rápidamente para atrapar las ideas que se le agolpaban en tropel, como el mismo dijo en alguna ocasión, y que le hacía escribir los finales de palabras, sistemáticamente, como una especie de línea continua o de un rasgo en que solo es discernible una letra que, sin embargo, puede incluir hasta tres letras o más. Además, con frecuencia empleaba abreviaturas propias que podían cambiar en el mismo texto aunque se refirieran a la misma palabra o nombre. En general, además de los rasgos propios de la caligrafía de la época, son más numerosos y difíciles de comprender los particulares de la escritura martiana. Ahora se está preparando un índice o guía de rasgos habituales de su caligrafía, a sabiendas que en muchas ocasiones una letra puede encontrarse con varias maneras de conformar sus rasgos.

En verdad, en más de una ocasión sólo se ha podido descifrar lo escrito gracias a las lecciones previas establecidas por las Obras completas impresas por los Quesadas, cuyo criterio de autoridad es incuestionable puesto que el padre fungió durante años como secretario de Martí en Nueva York y conocía perfectamente su caligrafía y a todas luces trasmitió muchos de esos "secretos" a su hijo, quien colaboró desde jovencito con él en la empresa de acopiar los documentos martianos y publicarlos. Tales transcripciones de los originales manuscritos han sido una escuela para quienes llevamos ya varios años descifrando la caligrafía del Maestro y es realmente asombroso y admirable que en 


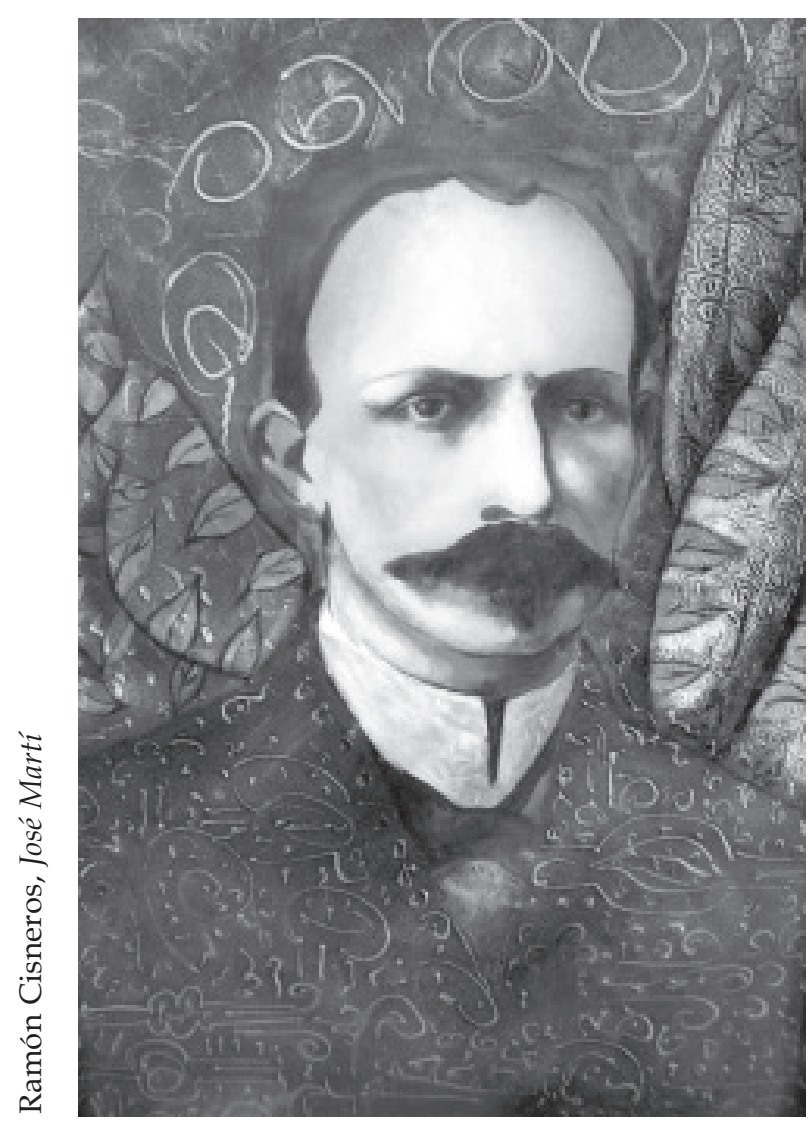

contados casos hayan cometido obvios errores o hayan declarado ilegible algunas palabras o frases que ahora sí hemos podido descifrar.

Fijar el texto en las tachaduras y enmiendas es una verdadera proeza de transcripción caligráfica, pues es muy común que las palabras queden sin terminar, usualmente están escritas con letra muy pequeña e intercaladas entre líneas, a veces con lápiz cuyo trazo se ha apagado con el tiempo, y las propias rayas que indican tachaduras ocultan a menudo los rasgos.

Se une a lo anterior, cuando se han conservado varias versiones de un mismo texto, el problema de establecer la cronología de escritura entre ellos, cuál precedió a otro. Para lograrlo, sobre todo cuando se trata de originales que Martí no envió a la imprenta, hay que someter el texto a un cuidadoso estudio, tanto de los aspectos formales de la caligrafía y las tintas de los documentos, como de estilo e ideas.

Con los impresos, los problemas son mucho más sencillos, aunque de la aplastante mayoría de lo que llegó a la imprenta no se conservan originales martianos, lo cual nos impide a veces precisar si hay erratas en el empleo de algunas palabras.

En este aspecto, la experiencia ha enseñado que no puede considerarse la errata sin consultar antes diccionarios de la lengua de los finales del siglo XIX y autoridades que describan las significaciones que han ido cayendo en desuso en el español actual. No puede pasarse por alto que Martí no sólo fue un conocedor y admirador profundo de los clásicos del Siglo de Oro, sino que conscientemente los incorporó a su propio estilo, y que su dominio de la lengua no puede ser calificado menos que de prodigioso en su creación literaria. Y como se ha señalado más de una vez, tenía madera de lingüista y gustaba de estudiar las variantes del español que entonces se hablaba en diferentes lugares, variantes que en muchas ocasiones escribió en sus textos.

Por otro lado, la lengua escrita de Martí está repleta de arcaísmos junto a atrevidos e ingeniosos neologismos perfectamente construidos en el plano gramatical, además de que obedecía las reglas ortográficas de su tiempo, bien diferentes a las nuestras.

$\mathrm{Su}$ estilo, tan original y auténtico, tampoco puede perderse de vista a la hora de fijar los textos, pues en más de un caso hay giros que hoy pueden ser quizás discutibles por ciertas normas de redacción, pero que en él son rasgos de su peculiaridad expresiva.

Quizás sea con los signos de puntuación el aspecto con que mayor cuidado hay que tener. El propio Martí escribió acerca de su necesidad de ampliar los signos para poder expresar su pensamiento. Tanto en impresos como en manuscritos a veces no se abre la admiración o la interrogación o el guión que indica la voz oral; hay momentos en que se tiene la certeza plena que se produjo la errata por los impresores, cuando, por ejemplo, se omite alguno de ellos dentro de un conjunto de frases en que sí aparecen. Al revisar los manuscritos, hay momentos en que todo parece indicar que en el apresuramiento de la escritura se olvidó el signo correspondiente; pero es evidente que en muchos casos el autor tuvo la voluntad expresa de omitirlos: quien sabe si porque en períodos muy largos quería enfatizar la entonación hacia el final del párrafo largo.

En todos los casos, el criterio editorial que guía a la edición crítica es respetar a Martí, sobre todo, si se trata de manuscritos originales de su puño y letra. Cuando se ha dispuesto de impresos corregidos por el propio autor, como ocurre con todos sus folletos y con sus dos cuadernos de poemas - de los que existen ejemplares de las ediciones príncipe-, se han admitido sus indicaciones al salvar las erratas. 
Con los periódicos, sin embargo, sólo se conservan manuscritos de dos o tres textos (versiones previas y quizás alguna copia de lo publicado) y es imposible determinar cuánto le fue modificado por los editores y hasta por los propios cajistas que tenían que montar los tipos, a no ser en los casos de nombres desconocidos por estos últimos. Por ello sólo se modifican los signos de puntuación cuando su uso es incongruente con la propia redacción (cuando no se conserva el habitual uso del punto y coma o de los dos puntos o de la pleca en una sucesión de frases) o cuando se trata de inobjetables normas gramaticales también de su tiempo (como la separación mediante comas en una enumeración). Y se señala en nota al pie que se sigue el original cuando la redacción puede parecer incongruente al lector actual.

Claro que se ha respetado con la mayor puntualidad los textos aparecidos en publicaciones bajo la responsabilidad editorial directa de Martí como la Revista Venezolana, La América, de Nueva York, y Patria, pues si hubo alguna censura fue la ejercida por el propio Martí sobre sí mismo. Incluso se ha examinado la labor editorial de los periódicos en que publicó con mayor frecuencia y de los que se dispone de colecciones (como la Revista Universal, de México; La Opinión Nacional, de Caracas; La Nación, de Buenos Aires, y El Partido Liberal, de México), a fin de medir el nivel de sus erratas y si lo publicado respondía a ciertas normas o carta de estilo propia.

Una de las labores más agotadoras, que ocupa más tiempo y que exige el máximo rigor y cuidado es la determinación de la autoría de textos publicados sin firma. Siempre se consideran el estilo, el ejercicio de la opinión tan sistemático en el periodismo martiano y las relaciones del contenido y los juicios con otros textos firmados. Cuando el menor elemento ofrece dudas, no se le atribuye su autoría y no se incluye el texto en la edición crítica.

Los Cuadernos de apuntes, en los que ya se trabaja, parecen ser en todos los casos manuscritos martianos; sin embargo, se trabaja con mucho cuidado en la búsqueda de autores que hayan tratado esos temas cuando hay indicios de que Martí copió textos ajenos, quizás para estudiarlos o conservarlos como fichas o anotaciones.

Fijado el texto martiano, que aporta numerosas notas aclaratorias sobre el mismo texto, contextuales y de referencias cruzadas sobre su propia obra, se continúa la elaboración de notas informativas y la búsqueda de información para los índices. Es impresionante la cantidad de personas, lugares y temas mencionados por Martí: en algún tomo pasan de cinco mil las entradas en los índices. Esta tarea exige la combinación de una amplia cultura martiana; de asuntos cubanos, latinoamericanos y estadounidenses; y de asuntos generales que abarcan desde la antigüedad clásica hasta el propio momento del siglo XIX en que él escribía. Por tal motivo, aunque el equipo realizador incluye estudiosos de vasta experiencia en la obra martiana, especializados en diversos temas y disciplinas, se ha hecho imprescindible acudir a las más variadas personas dentro y fuera de Cuba que puedan aclarar el asunto buscado.

Estas búsquedas son las que ocupan más tiempo dentro de la investigación y pueden convertirse en verdaderos estudios de aspectos desconocidos de la obra martiana, como ha ocurrido con el caso del hoy olvidado aventurero estadounidense Augustus K. Cutting, quien puso en seria afectación las relaciones entre México y Estados Unidos durante 1886, asunto que el cubano siguiera atentamente desde su periodismo, preocupado por el destino del país del Sur.

Particular dificultad suele ofrecer la identificación de las personas, títulos de obras artísticas y literarias aludidas por Martí sólo en algunos de sus rasgos o características y como dando por sabido el asunto.

Terminada la fase investigativa de cada tomo, las editoras trabajan con él directamente, revisan, unifican y completan todo lo hecho, entregan a diseño y realización, numeran los índices y revisan esas artes finales y la prueba de impresión. No se trata, por supuesto de una mera revisión, sino que su misión esencial es filtrar y completar cuanto hubiera escapado durante la investigación y cuidar el estricto cumplimiento de las Normas Editoriales.

De hecho, en la práctica, el investigador se hace editor, y el editor, investigador, y forman un equipo de trabajo integrado cuya tarea no termina hasta que el tomo está impreso.

Para los integrantes del equipo, las repetidas lecturas de los textos martianos y los análisis cuidadosos de sus contenidos para definir la necesidad de notas, se convierten en un estudio a fondo de sus diversos matices y significaciones literarias, lingüísticas, históricas, culturales y del pensamiento de su autor, del hombre y su tiempo, que es todo el hombre y todo el tiempo, como planteara hace muchos años Juan Marinello. 